\title{
Clinical impact of the immunome in lymphoid malignancies: the role of myeloid-derived suppressor cells
}

\author{
Calogero Vetro ${ }^{1}$, Alessandra Romano ${ }^{1 *}$, Flavia Ancora ${ }^{1}$, Francesco Coppolino ${ }^{2}$, \\ Maria V. Brundo ${ }^{3}$, Salvatore A. Raccuia ${ }^{3,4}$, Fabrizio Puglisi ${ }^{1}$, Daniele Tibullo ${ }^{1}$, \\ Piera La Cava ${ }^{1}$, Cesarina Giallongo ${ }^{1}$ and Nunziatina L. Parrinello ${ }^{1}$ \\ 'Division of Haematology, AOU "Policlinico - Vittorio Emanuele", University of Catania, Catania, Italy, ${ }^{2}$ Department of \\ Radiology, University of Palermo, Palermo, Italy, ${ }^{3}$ Department of Biological, Geological and Environmental Sciences, \\ University of Catania, Catania, Italy, ${ }^{4}$ National Research Council Institute for Agricultural and Forest Systems in the \\ Mediterranean, National Research Council, Catania, Italy
}

OPEN ACCESS

Edited by:

Sattva S. Neelapu,

The University of Texas M. D.

Anderson Cancer Center, USA

Reviewed by:

Robert Franklin Cornell,

Vanderbilt University Medical Center,

USA

Adetola A. Kassim,

Vanderbilt University Medical Center,

*Correspondence:

Alessandra Romano,

Division of Haematology, AOU

"Policlinico - Vittorio Emanuele",

University of Catania, Catania, Italy

sandrina.romano@gmail.com

Specialty section:

This article was submitted to Hematology Oncology, a section of the journal Frontiers in Oncology

Received: 23 February 2015 Accepted: 19 April 2015

Published: 21 May 2015

Citation:

Vetro C, Romano A, Ancora F, Coppolino F, Brundo MV, Raccuia SA, Puglisi F, Tibullo D, La Cava $P$, Giallongo $C$ and Parrinello NL (2015) Clinical impact

of the immunome in lymphoid

malignancies: the role of myeloid-derived suppressor cells.

Front. Oncol. 5:104.

doi: 10.3389/fonc.2015.00104
The better definition of the mutual sustainment between neoplastic cells and immune system has been translated from the bench to the bedside acquiring value as prognostic factor. Additionally, it represents a promising tool for improving therapeutic strategies. In this context, myeloid-derived suppressor cells (MDSCs) have gained a central role in tumor developing with consequent therapeutic implications. In this review, we will focus on the biological and clinical impact of the study of MDSCs in the settings of lymphoid malignancies.

Keywords: microenvironment, lymphoma, MDSCs, prognostication

\section{Introduction}

The study of microenvironment in hematological malignancies is becoming more and more intriguing. New soluble factors and cell-to-cell interactions are under investigation. In this complex network, myeloid-derived suppressor cells (MDSCs) represent a central hub. MDSCs are cells with suppressive habit, able to silence cytotoxic immune-response. This is due to the expression of two key enzymes, Arginase-1 (Arg-1) and the inducible form of nitric oxide synthase (iNOS). As a result, they are able to suppress T-cell response and to modulate regulatory T-cells (T-reg) functions. It is a real revolution in the field of immunological studies, in particular when applied to onco-hematological diseases.

\section{Pathogenetic and Clinical Importance of Tumor Microenvironment in Lymphoproliferative Disorders}

In order to better understand MDSC role in lymphoproliferative diseases, a brief overview on tumor microenvironment is required.

The tumor has been depicted as a mass of neoplastic cells for several years. However, recent studies have been demonstrating, both in solid and hematological tumors, an intricate cross-talk between neoplastic and inflammatory cells (1-3). Indeed, the immune system is able to create a fertile soil where neoplastic cells proliferate (4-7). It is usually composed by Th2 cytokines (such as IL-4, IL-10), angiogenetic factors (COX2, VEGF), and chemokines (CXCL12) $(4,8-10)$.

However, this cross-talk is not always clear and univocal. For example, compared to lymphoid hyperplasia, patients suffering from Hodgkin lymphoma $(\mathrm{HL})$ have a greater number of CD4+CD25+ cells, T-regulatory (T-reg) markers (11). Additionally, the greater the T-reg amount, the better 
the prognosis $(10,12,13)$. This would be justified by the fact that T-reg cells would be able to regulate the immune response, thus limiting tumor progression. However, the immune-escape and the ability to suppress T-cell response are required for $\mathrm{HL}$ development $(6,10)$ and Hodgkin-Reed Sternberg cells are themselves able to produce immunosuppressive factors, so that the higher the amount of FOXP3 positive cells (a transcription factor expressed by T-reg), the poorer the prognosis (14), being the mirror of the immune-escape of Hodgkin-Reed Sternberg cells. Quite similarly, in multiple myeloma (MM), clinical series indicated that the greater the bone marrow (BM) Treg amount, the more adverse the prognosis (15). However, there are no clear evidences, since in some studies the percentage of Treg into the $\mathrm{BM}$ is inferior compared to normal subjects (16), while in other studies, the number is increased (17). Additionally, in other reports, the amount of Treg is greater in the BM than peripheral blood (PB) (18). Indeed, a standard definition of MM features and Treg phenotype would be of great help in function definition (19) and such a perspective study is warranted. It has recently highlighted that the only positivity for FOXP3 expression is not a definitive and unique marker for Treg, being also characterized as $\mathrm{CD}^{+} \mathrm{CD}^{+} \mathrm{CD} 25^{+} \mathrm{CD} 127^{\text {low }}$ cells $(18,19)$.

Recently, a new subset of regulatory T-cells have been identified, i.e., Th17. The hallmark of these cells is IL-17 and IL-22 production and they are strictly dependent on IL-21, IL-22, IL-23, IL-27, and IL-6 $(16,20)$. Th17 amount is augmented in both PB and BM of MM patients. Additionally, MM-plasma cells (PC) express on cell surface the IL-17R (receptor of IL-17) (16) and its amount relate with lytic lesions (21), tumor stage, serum lactate dehydrogenase concentration, and serum creatinine concentration (22). Additionally, this effect is reverted when a Th1 BM enrichment is induced (21).

Apart from the lymphoid axis, an intricate cross-talk exists with the myeloid subset, especially with tumor-associated macrophages (TAMs). TAMs have a pivotal role in regulating lymphoma behavior in several histotypes, including Hodgkin's lymphoma (23), nonHodgkin lymphoma (NHL), and follicular lymphoma (FL) (24). In several hematological tumors, macrophages are able to address the behavior of the entire microenvironment and also of neoplastic cells, especially in early stages of the disease (10). This fact makes these cells as essential for tumor promotion phase. By secreting TGF- $\beta$ and IL-10 (25), suppressing T-cell activation (26), and promoting angiogenesis $(25,27)$, TAMs favor the immune-escape of the tumor $(25,28,29)$. Many studies correlated the increase of TAMs in tumor context with tumor angiogenesis, metastasis, and tumor progression $(10,24,28-30)$. Additionally, the amount of TAMs positively relate with the tumor mass and stage.

Thus, it seems that the microenvironment is essential in the early phases of disease development, and continues to guarantee a permissible milieu to neoplastic cells during tumor growth. Thereafter, neoplastic cells become independent from the microenvironment.

Despite initial encouraging observations reported above, lack of reproducibility, discordant and not confirmative recent studies, and inconsistency of scoring are currently considered potential pitfalls for the routine use of TAMs as biomarkers, leading some authors to not agree with the prognostic power of CD68+ infiltrate (31).

\section{Myeloid-Derived Suppressor Cells and Their Role in Tumor Microenvironment}

Myeloid-derived suppressor cells have been recently identified in solid (32) and hematological (33) cancers as a heterogeneous population of immature and mature cells of myeloid origin that are home to the tumors and contribute indirectly to angiogenesis, growth, and metastasis (34). They originate on the BM, but acquire the ability to home into secondary lymphoid organs (35) and also in tumors mass $(36,37)$. Indeed, they are able to migrate into liver, inducing a suppressive habit to Kupfer cells (through the over-expression of PDL1) able to silence T-cell function through Arginase-1 (Arg-1) release. Furthermore, they are able to migrate into tumor context where they exhibit the immunosuppressive function (35). Interestingly, Arginase activity into tumor context is greater than in $\mathrm{PB}$ (35).

This homing capability has two important consequences. First, marking MDSCs; it is possible to follow the homing phase without sacrificing mouse models. Second, MDSCs can be used as therapeutic vehicle (38).

Morphologically, two subsets can be identified: granulocytes (N-MDSCs) or monocytes (mo-MDSCs) (39, 40), possessing, respectively, a polymorphonuclear or monocytic feature. First identification of MDSCs markers was from mouse models where granulocytic MDSCs are identified as CD11b+ $\mathrm{LY}^{+} \mathrm{G}^{+} \mathrm{LY}^{\mathrm{low}}$ cells, while monocytic MDSCs are CD11b+LY6G-LY6Chigh (39, 41). Due to the lack of LY6G and LY6C on human cells, the definition of MDSCs in human is still argued. Basically, moMDSCs are defined as CD14 ${ }^{+} \mathrm{HLA}-\mathrm{DR}^{\text {low/- }}$ and G-MDSCs as

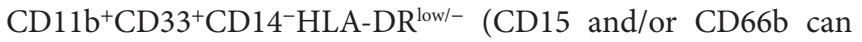
also be positive) $(32,40)$. Prior studies introduced also a subset of immature MDSCs CD34+ (im-MDSCs) (42).

Apart from morphological and immunophenotipicidentification, the definition of MDSCs relies on their functional properties and suppressive activities. MDSCs can induce T-cell tolerance through the expression of Arg-1. In fact, starving lymphocytes, depleting Arginine, reduce significantly their function leading to a cell cycle arrest in G0/G1 stage, due to a repression of cyclin production. Contrarily, treatment with Nor-NOHA or NOHA (an Arg-I inhibitor) is able to revert the immune-suppressive ability of MDSCs. Interestingly, this pathway is more pronounced in G-MDSCs (43), while Mo-MDSCs deplete the available arginine through NOS2 activity (39). The overproduction of nitric oxide leads to augmented levels of peroxynitrite and nitrotyrosine. This is peculiar to silence TCR pathways and thus T-cell function $(32,39,44)$, promoting the escape from immune-surveillance $(34,45)$. T and NK cell dysfunction induced by MDSCs can in turn favor the aberrant MDSCs dismissing in a pathological loop $(32,34,41,45)$. Lately, recent investigations suggested that MDSCs are also the progenitors of TAMs in the BM $(32,46)$. MDSCs can also produce a large amount of cytokines, able to drive the microenvironment toward a pro-tumoral background ambient $(35,46)$. Producing IL-10, MDSCs can decrease the amount of IL- 6 and TNF- $\alpha$, increasing NO.

The elaborate cross-talk between macrophages, MDSCs, and tumor cells result in differential production of IL-6, IL-10, TNF- $\alpha$, and NO, suggesting that the interaction between these cells has the potential to significantly alter the inflammatory milieu within the 
tumor microenvironment $(2,3,40,47)$. This fact makes MDSCs noteworthy to be studied in hematological tumor. Additionally, they would represent a valid and reliable marker to be used in these malignancies since their presence in $\mathrm{PB}$ is guaranteed by the homing ability.

\section{Clinical Progress in MDSC Study and Applications}

Studies on MDSCs in hematological malignancies are increasing since the better definition of this cellular subtype and its functional analysis. The peculiar MDSCs function and activity, together with the ability to isolate them from $\mathrm{BM}$ and $\mathrm{PB}$ has led many groups to focus on their study (48). Translating these evidences to the clinical practice, several studies are emerging with important prognostic and therapeutic consequences in both HL and NHL $(2,3)$.

Pivotal studies by Lin et al. (49) found that a subpopulation of $\mathrm{CD}_{14}+\mathrm{HLA}^{-\mathrm{DR}}{ }^{-/ \text {low }}$ monocytes exert immunosuppressive function in NHL patients by depleting arginine bioavailability through Arg-1 activity. In particular, monocytes were able to abrogate Th1 lymphocyte activation to antigen stimulation, with a fivefold decrease in the secretion of IFN- $\gamma$. Interestingly, the proliferation rate of patients' lymphocytes was restored when suppressive monocytes were depleted from the medium. The monocytes were also impaired itself in their functions, due to the reduced levels of pSTAT1 expression and reduced ability to produce IFN- $\gamma$. Additionally, the higher the amount of suppressive monocytes, the more adverse the prognosis. The monocytes were also rich in Arg-1 production, and serum from NHL patients had higher levels of ARG-1 compared to control. Additionally, the levels of Arg-1 related with suppressive monocytes. Later, this highlights the identification of MDSCs as central in tumor escape. Indeed, in the A20 murine model, Serafini et al. found that the immune-escape depends strictly on MDSCs [defined as activity that is able to expand selectively Treg (CD25+/FOXP3+)] (50). Interestingly, treatment with L-NMMA and/or NOHA reverted the immunosuppressive feature by suppressing Arg-1 and/or iNOS activity. The combination with both drugs completely reverted the immunosuppressive feature.

Among lymphoma subtypes, diffuse large B-cell lymphoma (DLBCL) has the greatest amount of suppressive monocytes followed by FL and indolent lymphomas (49). Recently, in a limited cohort of 23 DLBCL patients, PB mo-MDSCs have been evaluated as $\mathrm{CD}_{14}{ }^{+} / \mathrm{HLA}-\mathrm{DR}^{-}$cells (51). Additionally, DLBCL patients have a greater amount of Mo-MDSCs on $\mathrm{PB}$ compared

\section{References}

1. Bizzarri M, Cucina A. Tumor and the microenvironment: a chance to reframe the paradigm of carcinogenesis?Biomed Res Int (2014) 2014:934038. doi:10.1155/2014/934038

2. Romano A, Conticello C, Cavalli M, Vetro C, La Fauci A, Parrinello NL, et al. Immunological dysregulation in multiple myeloma microenvironment. Biomed Res Int (2014) 2014:198539. doi:10.1155/2014/198539

3. Romano A, Vetro C, Caocci G, Greco M, Parrinello NL, Di Raimondo F, et al. Immunological deregulation in classic Hodgkin lymphoma. Mediterr J Hematol Infect Dis (2014) 6:e2014039. doi:10.4084/MJHID.2014.039 to healthy control and, when complete remission is achieved, their values return to be equal to healthy control. However, the small number of patients did not lead the authors to conclude a direct correlation between monocytosis and mo-MDSCs. Interestingly, only three patients among a total of five patients with monocytosis showed augmented levels of Mo-MDSCs.

In HL, the inflammation is the hallmark of the disease (52). HL patients have a greater amount of MDSCs compared to healthy control (53-55) and, to date, we have been able to identify the three main MDSCs subsets, i.e., G-MDSCs, Mo-MDSCs, and im-MDSCs. However, only CD34+ cells (im-MDSCs) seem to relate with prognosis in HL patients, even though treated upfront with a risk-adapted therapy (56). At diagnosis, HL patients showed higher levels of MDSCs subsets compared to matched healthy controls. Additionally, the greater the tumor mass, the greater the MDSCs count, reflecting the disease stage and aggressiveness. Regarding the clinical outcome, after 34 months of follow-up, im-MDSCs were the only subset related to clinical outcome. On the contrary, mo-MDSCs and G-MDSCs failed to show a prognostic impact. In particular, setting a cut-off level of 4.5 cells $/ \mu \mathrm{L}$, im-MDSCs showed a sensitivity and specificity $>85 \%$ and a specificity greater than $70 \%$ in both early and advanced stage disease. Median progression-free survival (PFS) in patients with high levels of MDSCs was 14.7 months compared to a not reached median of the low count group. The prognostic value of im-MDSCs was retained also applying the multivariate analysis. In addition, MDSCs count can add information to the most important prognostic factor in HD, i.e., positive positron emission tomography (PET) after two cycles of chemotherapy (PET-2). An additional advantage of im-MDSCs count over PET-2 would be the availability at diagnosis. Moreover, the combination of MDSCs count and PET-2 evaluation allows to define three different groups of patients with different outcome (56).

\section{Conclusion}

The study of the immunome has become more and more intricate with new factors and cell-to-cell interactions discovered. An emerging role is played by the study of the myeloid dysfunction as a central hub in the complex network depicting the disease. Even if more studied on solid tumors, MDSCs are a reliable tool also in hematological malignancies, in particular in the setting of lymphoid malignancies. Additionally, the emerging reports in clinical settings are making them worth to be studied and used as prognostic factor.

4. Dave SS, Wright G, Tan B, Rosenwald A, Gascoyne RD, Chan WC, et al. Prediction of survival in follicular lymphoma based on molecular features of tumor-infiltrating immune cells. N Engl J Med (2004) 351:2159-69. doi:10.1056/ NEJMoa041869

5. Fozza C, Corda G, Virdis P, Contini S, Barraqueddu F, Galleu A, et al. Derangement of the T-cell repertoire in patients with B-cell non-Hodgkin's lymphoma. Eur J Haematol (2014) 94(4):298-309. doi:10.1111/ejh.12417

6. Schreck S, Friebel D, Buettner M, Distel L, Grabenbauer G, Young LS, et al. Prognostic impact of tumour-infiltrating Th2 and regulatory T cells in classical Hodgkin lymphoma. Hematol Oncol (2009) 27:31-9. doi:10.1002/ hon. 878 
7. Aldinucci D, Gloghini A, Pinto A, De Filippi R, Carbone A. The classical Hodgkin's lymphoma microenvironment and its role in promoting tumour growth and immune escape. J Pathol (2010) 221:248-63. doi:10.1002/path.2711

8. Sharma A, Khan R, Joshi S, Kumar L, Sharma M. Dysregulation in T helper 1/T helper 2 cytokine ratios in patients with multiple myeloma. Leuk Lymphoma (2010) 51:920-7. doi:10.3109/10428191003699563

9. Bertilaccio MT, Scielzo C, Muzio M, Caligaris-Cappio F. An overview of chronic lymphocytic leukaemia biology. Best Pract Res Clin Haematol (2010) 23:21-32. doi:10.1016/j.beha.2009.12.005

10. Steidl C, Connors JM, Gascoyne RD. Molecular pathogenesis of Hodgkin's lymphoma: increasing evidence of the importance of the microenvironment. $J$ Clin Oncol (2011) 29:1812-26. doi:10.1200/JCO.2010.32.8401

11. Hudnall SD, Betancourt E, Barnhart E, Patel J. Comparative flow immunophenotypic features of the inflammatory infiltrates of Hodgkin lymphoma and lymphoid hyperplasia. Cytometry B Clin Cytom (2008) 74:1-8. doi:10.1002/cyto.b.20376

12. Tzankov A, Meier C, Hirschmann P, Went P, Pileri SA, Dirnhofer S. Correlation of high numbers of intratumoral FOXP3 + regulatory $\mathrm{T}$ cells with improved survival in germinal center-like diffuse large B-cell lymphoma, follicular lymphoma and classical Hodgkin's lymphoma. Haematologica (2008) 93:193-200. doi:10.3324/ haematol.11702

13. Alvaro T, Lejeune M, Salvadó MT, Bosch R, García JF, Jaén J, et al. Outcome in Hodgkin's lymphoma can be predicted from the presence of accompanying cytotoxic and regulatory T cells. Clin Cancer Res (2005) 11:1467-73. doi:10.1158/10780432.CCR-04-1869

14. Greaves P, Clear A, Coutinho R, Wilson A, Matthews J, Owen A, et al. Expression of FOXP3, CD68, and CD20 at diagnosis in the microenvironment of classical Hodgkin lymphoma is predictive of outcome. J Clin Oncol (2013) 31:256-62. doi:10.1200/JCO.2011.39.9881

15. Beyer M, Kochanek M, Giese T, Endl E, Weihrauch MR, Knolle PA, et al. In vivo peripheral expansion of naive $\mathrm{CD} 4+\mathrm{CD} 25$ high FoxP3+ regulatory $\mathrm{T}$ cells in patients with multiple myeloma. Blood (2006) 107:3940-9. doi:10.1182/ blood-2005-09-3671

16. Prabhala RH, Pelluru D, Fulciniti M, Prabhala HK, Nanjappa P, Song W, et al. Elevated IL-17 produced by TH17 cells promotes myeloma cell growth and inhibits immune function in multiple myeloma. Blood (2010) 115:5385-92. doi:10.1182/ blood-2009-10-246660

17. Prabhala RH, Neri P, Bae JE, Tassone P, Shammas MA, Allam CK, et al. Dysfunctional T regulatory cells in multiple myeloma. Blood (2006) 107:301-4. doi:10.1182/blood-2005-08-3101

18. Favaloro J, Brown R, Aklilu E, Yang S, Suen H, Hart D, et al. Myeloma skews regulatory $\mathrm{T}$ and pro-inflammatory $\mathrm{T}$ helper 17 cell balance in favor of a suppressive state. Leuk Lymphoma (2013) 55(5):1090-8. doi:10.3109/10428194.2013.825905

19. Beyer M, Classen S, Endl E, Kochanek M, Weihrauch MR, Debey-Pascher S, et al. Comparative approach to define increased regulatory $\mathrm{T}$ cells in different cancer subtypes by combined assessment of CD127 and FOXP3. Clin Dev Immunol (2011) 2011:734036. doi:10.1155/2011/734036

20. Wang M, Tian T, Yu S, He N, Ma D. Th17 and Treg cells in bone related diseases. Clin Dev Immunol (2013) 2013:203705. doi:10.1155/2013/203705

21. Noonan K, Marchionni L, Anderson J, Pardoll D, Roodman GD, Borrello I. A novel role of IL-17-producing lymphocytes in mediating lytic bone disease in multiple myeloma. Blood (2010) 116:3554-63. doi:10.1182/blood-2010-05-283895

22. Shen CJ, Yuan ZH, Liu YX, Hu GY. Increased numbers of Thelper 17 cells and the correlation with clinicopathological characteristics in multiple myeloma. Int Med Res (2012) 40:556-64. doi:10.1177/147323001204000217

23. Steidl C, Farinha P, Gascoyne RD. Macrophages predict treatment outcome in Hodgkin's lymphoma. Haematologica (2011) 96:186-9. doi:10.3324/ haematol.2010.033316

24. Canioni D, Salles G, Mounier N, Brousse N, Keuppens M, Morchhauser F, et al. High numbers of tumor-associated macrophages have an adverse prognostic value that can be circumvented by rituximab in patients with follicular lymphoma enrolled onto the GELA-GOELAMS FL-2000 trial. J Clin Oncol (2008) 26:440-6. doi:10.1200/JCO.2007.12.8298

25. Coffelt SB, Hughes R, Lewis CE. Tumor-associated macrophages: effectors of angiogenesis and tumor progression. Biochim Biophys Acta (2009) 1796:11-8. doi:10.1016/j.bbcan.2009.02.004

26. Hagemann T, Biswas SK, Lawrence T, Sica A, Lewis CE. Regulation of macrophage function in tumors: the multifaceted role of NF-kappaB. Blood (2009) 113:3139-46. doi:10.1182/blood-2008-12-172825
27. Porta C, Larghi P, Rimoldi M, Totaro MG, Allavena P, Mantovani A, et al. Cellular and molecular pathways linking inflammation and cancer. Immunobiology (2009) 214:761-77. doi:10.1016/j.imbio.2009.06.014

28. Steidl C, Lee T, Shah SP, Farinha P, Han G, Nayar T, et al. Tumor-associated macrophages and survival in classic Hodgkin's lymphoma. N Engl J Med (2010) 362:875-85. doi:10.1056/NEJMoa0905680

29. Tan KL, Scott DW, Hong F, Kahl BS, Fisher RI, Bartlett NL, et al. Tumor-associated macrophages predict inferior outcomes in classic Hodgkin lymphoma: a correlative study from the E2496 Intergroup trial. Blood (2012) 120:3280-7. doi:10.1182/ blood-2012-04-421057

30. Ribatti D, Moschetta M, Vacca A. Macrophages in multiple myeloma. Immunol Lett (2014) 161:241-4. doi:10.1016/j.imlet.2013.12.010

31. Azambuja D, Natkunam Y, Biasoli I, Lossos IS, Anderson MW, Morais JC, et al. Lack of association of tumor-associated macrophages with clinical outcome in patients with classical Hodgkin's lymphoma. Ann Oncol (2012) 23:736-42. doi:10.1093/annonc/mdr157

32. Gabrilovich DI, Ostrand-Rosenberg S, Bronte V. Coordinated regulation of myeloid cells by tumours. Nat Rev Immunol (2012) 12:253-68. doi:10.1038/nri3175

33. Brimnes MK, Vangsted AJ, Knudsen LM, Gimsing P, Gang AO, Johnsen HE, et al. Increased level of both $\mathrm{CD} 4+\mathrm{FOXP} 3+$ regulatory $\mathrm{T}$ cells and $\mathrm{CD} 14^{+} \mathrm{HLA}^{-\mathrm{DR}^{-}} /$ low myeloid-derived suppressor cells and decreased level of dendritic cells in patients with multiple myeloma. Scand J Immunol (2010) 72:540-7. doi:10.1111/j.1365-3083.2010.02463.x

34. Nagaraj S, Collazo M, Corzo CA, Youn JI, Ortiz M, Quiceno D, et al. Regulatory myeloid suppressor cells in health and disease. Cancer Res (2009) 69:7503-6. doi:10.1158/0008-5472.CAN-09-2152

35. Schlecker E, Stojanovic A, Eisen C, Quack C, Falk CS, Umansky V, et al. Tumorinfiltrating monocytic myeloid-derived suppressor cells mediate CCR5-dependent recruitment of regulatory T cells favoring tumor growth. J Immunol (2012) 189:5602-11. doi:10.4049/jimmunol.1201018

36. Ilkovitch D, Lopez DM. The liver is a site for tumor-induced myeloid-derived suppressor cell accumulation and immunosuppression. Cancer Res (2009) 69:5514-21. doi:10.1158/0008-5472.CAN-08-4625

37. Capuano G, Rigamonti N, Grioni M, Freschi M, Bellone M. Modulators of arginine metabolism support cancer immunosurveillance. BMC Immunol (2009) 10:1. doi:10.1186/1471-2172-10-1

38. Eisenstein S, Coakley BA, Briley-Saebo K, Ma G, Chen HM, Meseck M, et al. Myeloid-derived suppressor cells as a vehicle for tumor-specific oncolytic viral therapy. Cancer Res (2013) 73:5003-15. doi:10.1158/0008-5472.CAN-12-1597

39. Youn JI, Nagaraj S, Collazo M, Gabrilovich DI. Subsets of myeloid-derived suppressor cells in tumor-bearing mice. J Immunol (2008) 181:5791-802. doi:10.4049/ jimmunol.181.8.5791

40. Romano A, Vetro C, Adriani M. Advances in understanding regulatory myeloid cells. Cancer Biol Ther (2011) 11:923-6. doi:10.4161/cbt.11.11.15541

41. Gabrilovich DI, Nagaraj S. Myeloid-derived suppressor cells as regulators of the immune system. Nat Rev Immunol (2009) 9:162-74. doi:10.1038/nri2506

42. Ostrand-Rosenberg S, Sinha P. Myeloid-derived suppressor cells: linking inflammation and cancer. J Immunol (2009) 182:4499-506. doi:10.4049/ jimmunol.0802740

43. Rodriguez PC, Quiceno DG, Zabaleta J, Ortiz B, Zea AH, Piazuelo MB, et al. Arginase I production in the tumor microenvironment by mature myeloid cells inhibits T-cell receptor expression and antigen-specific T-cell responses. Cancer Res (2004) 64:5839-49. doi:10.1158/0008-5472.CAN-04-0465

44. Nagaraj S, Gupta K, Pisarev V, Kinarsky L, Sherman S, Kang L, et al. Altered recognition of antigen is a mechanism of $\mathrm{CD} 8+\mathrm{T}$ cell tolerance in cancer. Nat Med (2007) 13:828-35. doi:10.1038/nm1609

45. Youn JI, Gabrilovich DI. The biology of myeloid-derived suppressor cells: the blessing and the curse of morphological and functional heterogeneity. Eur $J$ Immunol (2010) 40:2969-75. doi:10.1002/eji.201040895

46. Marigo I, Dolcetti L, Serafini P, Zanovello P, Bronte V. Tumor-induced tolerance and immune suppression by myeloid derived suppressor cells. Immunol Rev (2008) 222:162-79. doi:10.1111/j.1600-065X.2008.00602.x

47. Parrinello N, Di Raimondo F, Romano A. Myeloid derived suppressor cells in multiple myeloma. Exp Rev Immunol Vaccine (2014) 1:14-20.

48. Tadmor T, Attias D, Polliack A. Myeloid-derived suppressor cells - their role in haemato-oncological malignancies and other cancers and possible implications for therapy. Br J Haematol (2011) 153:557-67. doi:10.1111/j.1365-2141.2011.08678.x 
49. Lin Y, Gustafson MP, Bulur PA, Gastineau DA, Witzig TE, Dietz AB. Immunosuppressive CD14+HLA-DR(low)/- monocytes in B-cell non-Hodgkin lymphoma. Blood (2011) 117:872-81. doi:10.1182/blood-2010-05-283820

50. Serafini P, Mgebroff S, Noonan K, Borrello I. Myeloid-derived suppressor cells promote cross-tolerance in B-cell lymphoma by expanding regulatory $\mathrm{T}$ cells. Cancer Res (2008) 68:5439-49. doi:10.1158/0008-5472.CAN-07-6621

51. Tadmor T, Fell R, Polliack A, Attias D. Absolute monocytosis at diagnosis correlates with survival in diffuse large B-cell lymphoma-possible link with monocytic myeloid-derived suppressor cells. Hematol Oncol (2013) 31:65-71. doi:10.1002/ hon. 2019

52. Vetro C, Romano A, Fiumara P, Donnarumma D, Chiarenza A, Figuera A, et al. Inflammatory markers assessment at diagnosis can improve the risk assessment of Hodgkin lymphoma patients. Annals of Oncology. Oxford: Oxford University Press (2011). p. 238-238.

53. Romano A, Vetro C, Parrinello NL, Donnarumma D, Chiarenza A, Figuera A, et al. Prognostic value of myeloid impairment in Hodgkin's lymphoma. Annals of Oncology. Oxford: Oxford University Press (2011). p. 143-143.

54. Romano A, Parrinello N, Vetro C, La Cava P, Giallongo C, Tibullo A, et al. Myeloid cells exert immunosuppressive activity and have prognostic value in Hodgkin lymphoma. Blood (2013) 122:4238-4238.
55. Romano A, Parrinello N, Vetro C, La Cava P, Donnarumma D, Conticello C, et al. Absolute count of myeloid derived suppressor cells (MDSC) is able to predict the response to early-PET in Hodgkin lymphoma. Blood. Washington, DC: American Society of Hematology (2010). p. 1585-6.

56. Romano A, Parrinello NL, Vetro C, Forte S, Chiarenza A, Figuera A, et al. Circulating myeloid-derived suppressor cells correlate with clinical outcome in Hodgkin Lymphoma patients treated up-front with a risk-adapted strategy. $\mathrm{Br} J$ Haematol (2014) 168(5):689-700. doi:10.1111/bjh.13198

Conflict of Interest Statement: The authors declare that the research was conducted in the absence of any commercial or financial relationships that could be construed as a potential conflict of interest.

Copyright $\odot 2015$ Vetro, Romano, Ancora, Coppolino, Brundo, Raccuia, Puglisi, Tibullo, La Cava, Giallongo and Parrinello. This is an open-access article distributed under the terms of the Creative Commons Attribution License (CC BY). The use, distribution and reproduction in other forums is permitted, provided the original author(s) or licensor are credited and that the original publication in this journal is cited, in accordance with accepted academic practice. No use, distribution or reproduction is permitted which does not comply with these terms. 